Article

\title{
Enhancement of the Solubility and Bioavailability of Pitavastatin through a Self-Nanoemulsifying Drug Delivery System (SNEDDS)
}

\author{
Mehran Ashfaq ${ }^{1}$, Shahid Shah ${ }^{2, *(D)}$, Akhtar Rasul ${ }^{1}$ (D), Muhammad Hanif ${ }^{3}$, Hafeez Ullah Khan ${ }^{4}$,
} Ahmed Khames ${ }^{5}$ (D) Mohamed A. Abdelgawad ${ }^{6}$ (D), Mohammed M. Ghoneim ${ }^{7}$ (D), Muhammad Yasir Ali ${ }^{1}$, Mohammad A. S. Abourehab ${ }^{8,9}$ (D), Safirah Maheen ${ }^{4}$, Omeira Iqbal ${ }^{1}$, Ghulam Abbas ${ }^{1, *(D)}$ and Amani M. El Sisi ${ }^{10}$

check for updates

Citation: Ashfaq, M.; Shah, S.; Rasul, A.; Hanif, M.; Khan, H.U.; Khames, A.; Abdelgawad, M.A.; Ghoneim, M.M.; Ali, M.Y.; Abourehab, M.A.; et al. Enhancement of the Solubility and Bioavailability of Pitavastatin through a Self-Nanoemulsifying Drug Delivery System (SNEDDS). Pharmaceutics 2022, 14, 482. https://doi.org/10.3390/ pharmaceutics14030482

Academic Editors: Ionela Andreea Neacsu and Bogdan Stefan Vasile

Received: 18 January 2022 Accepted: 18 February 2022 Published: 22 February 2022

Publisher's Note: MDPI stays neutral with regard to jurisdictional claims in published maps and institutional affiliations.

Copyright: () 2022 by the authors Licensee MDPI, Basel, Switzerland. This article is an open access article distributed under the terms and conditions of the Creative Commons Attribution (CC BY) license (https:// creativecommons.org/licenses/by/ $4.0 /)$.
1 Department of Pharmaceutics, Faculty of Pharmaceutical Sciences, Government College University, Faisalabad 38000, Pakistan; mehran.ashfaq@pkli.org.pk (M.A.); akhtar.rasul@gcuf.edu.pk (A.R.); myasirali@gcuf.edu.pk (M.Y.A.); pharmacist@carepharmacy.com.pk (O.I.)

2 Department of Pharmacy Practice, Faculty of Pharmaceutical Sciences, Government College University, Faisalabad 38000, Pakistan

3 Department of Pharmaceutics, Faculty of Pharmacy, Bahauddin Zakariya University, Multan 60000, Pakistan; muhammad.hanif@bzu.edu.pk

4 Department of Pharmaceutics, College of Pharmacy, University of Sargodha, Sargodha 40100, Pakistan; hafeezullah.khan@uos.edu.pk (H.U.K.); safirah.maheen@uos.edu.pk (S.M.)

5 Department of Pharmaceutics and Industrial Pharmacy, College of Pharmacy, Taif University, Taif 21944, Saudi Arabia; a.khamies@tu.edu.sa

6 Department of Pharmaceutical Chemistry, College of Pharmacy, Jouf University, Sakaka 72341, Saudi Arabia; mhmdgwd@ju.edu.sa

7 Department of Pharmacy Practice, Faculty of Pharmacy, AlMaarefa University, Ad Diriyah 13713, Saudi Arabia; mghoneim@mcst.edu.sa

8 Department of Pharmaceutics, Faculty of Pharmacy, Umm Al-Qura University, Makkah 21955, Saudi Arabia; maabourehab@uqu.edu.sa

9 Department of Pharmaceutics and Industrial Pharmacy, College of Pharmacy, Minia University, Minia 61519, Egypt

10 Department of Pharmaceutics and Industrial Pharmacy, Faculty of Pharmacy, Beni-Suef University, Beni-Suef 62514, Egypt; amany.elsese@pharma.bsu.edu.eg

* Correspondence: shahid.shah@gcuf.edu.pk (S.S.); ghulamabbas@gcuf.edu.pk (G.A.)

\begin{abstract}
The purpose of the study was to develop an SNEDDS to improve the solubility and bioavailability of pitavastatin. The solubility of pitavastatin in different oils, surfactants, and Cosurfactants was determined and a pseudo-ternary phase diagram was constructed. The SNEDDS was characterized by zeta-sizer, zeta-potential, FTIR, DSC, and TGA. Release and permeation of pitavastatin from the SNEDDS was studied for 12 and $24 \mathrm{~h}$, respectively. The lipolysis test, RBC lysis, effect on lipid profile, and pharmacokinetics were studied. The SPC3 formulation showed a $104 \pm 1.50 \mathrm{~nm}$ particle size, a 0.198 polydispersity index (PDI), and a -29 zeta potential. FTIR, DSC, and TGA showed the chemical compatibility and thermal stability. The release and permeation of pitavastatin from SPC3 was $88.5 \pm 2.5 \%$ and $96 \%$, respectively. In the lipolysis test, the digestion of SPC3 yielded a high amount of pitavastatin and showed little RBC lysis. The lipid profile suggested that after 35 days of administration of the SNEDDS, there was a marked decrease in TC, LDL, and triglyceride levels. The SNEDDS of SPC3 showed an $86 \%$ viability of Caco- 2 cells. Pharmacokinetics of SPC 3 showed improved values of $C_{\max }, T_{\max }$, half-life, MRT, AUC, and AUMC compared to the reference formulation. Our study demonstrated that the SNEDDS effectively enhanced the solubility and bioavailability of a BCS class II drug.
\end{abstract}

Keywords: nanoemulsion; pitavastatin; drug release; cytotoxicity; pharmacokinetics 


\section{Introduction}

Hyperlipidemia is a condition in which there are increased amounts of lipids in the blood. Modern primary care physicians spend a lot of time and money on preventive medicine. Diagnosis and treatment of hyperlipidemia as a means of preventing cardiovascular disease is a common practice of primary care physicians [1]. After hypertension, hyperlipidemia ranks as the second leading condition among the 10 most common chronic conditions observed, according to data from the Centers for Disease Control from a study of 1492 physicians [2]. Several clinical trials have shown that statins successfully lower low-density lipoprotein and lower cardiovascular danger in individuals with dyslipidemia and metabolic disorder [3].

The oral route is the most common, efficient, profitable, and feasible route for administration. Although it has several disadvantages, such as the first pass effect, low bioavailability, low stability, it is the most adoptive approach to administer the drug due to the high rate of patient compliance [4]. Pitavastatin, which belongs to a class of statins, is a synthetic inhibitor of HMG-CoA reductase that has a cyclopropyl group. It is indicated to minimize elevated levels of total cholesterol (TC), low-density lipoprotein cholesterol (LDL-C), apo-lipoprotein B (Apo B), triglycerides (TGs), and improve high-density lipoprotein cholesterol (HDL-C) in the treatment of adult patients with primary hyperlipidemia or mixed dyslipidemia. It is also recommended for the care of pediatric patients 8 years of age and older with heterozygous familial hypercholesterolemia $(\mathrm{HeFH})$ to minimize elevated TC, LDL-C, and Apo B [5]. It has the same effects as other statins, that is, pravastatin, atorvastatin, and simvastatin but at a very low dose [6].

Pitavastatin belongs to the BCS class II; therefore, it has low solubility and bioavailability. It is metabolized in the liver by glucuronidation and is excreted through urine and feces. Because of this, bypassing the liver metabolism and improving the solubility of pitavastatin is an attractive approach to enhancing its therapeutic effect. Different approaches have been taken for the delivery of poorly soluble drugs, e.g., solid dispersion, particle size reduction, co-precipitation, and lipid-based drug delivery systems $[7,8]$.

A lipid-based or lipid-carrier drug delivery system is a promising technique that has been used to improve the oral bioavailability of less soluble drugs. The primary goal of the lipid-based formulation is to minimize liver degradation and increase the bioavailability of drugs [9]. A self-emulsifying drug delivery system (SEDDS) is one of the lipid-based drug delivery systems currently being studied for its advantages: it provides a wide interfacial region to separate the drug between oil and gastrointestinal fluid. This technique increases the oral bioavailability of poorly soluble drugs by increasing the solubility and preserving the drug in a dissolved state, in small oil droplets, during its passage through the gastrointestinal tract [10]. In an SEDDS, when the emulsion droplet size is in the nanometer range, this formulation can be called an SNEDDS.

The SNEDDS has been more systematically characterized from a physicochemical point of view among lipid-based formulations. SNEDDS are an isotropic mixture of oil, surfactant, and co-surfactant with gentle agitation, which after interaction with water, join together to form an emulsion. An SNEDDS normally produces droplet sizes in the range of 20-200 nm after dilution. The prepared nano-sized droplets can provide improved dissolution rates as well as bioavailability. SNEDDS are generally more mechanically and physically stable compared to other conventional preparations (emulsion) and easy to prepare both on a small and large scale. The rationale for using SNEDDS for the delivery of less soluble drugs is that they can be obtained as a pre-concentrated solution, which will avoid the dissolution step. Furthermore, the development of various colloidal species in the dispersal and subsequent digestion of the SNEDDS promotes drug absorption [11,12]. The present study aimed to develop an SNEDDS of pitavastatin in order to enhance its solubility and bioavailability. 


\section{Materials and Methods}

\subsection{Materials}

Pitavastatin was obtained as a gift sample from CCL Laboratories Pvt., Ltd., Lahore, Pakistan. PEG 200, PEG 400, PEG 600, cinnamon oil, olive oil, ginger oil, sesame oil, virgin coconut oil, and castor oil were purchased from Sigma-Aldrich Gmbh, Darmstadt, Germany. Methanol, acetonitrile, Tween 20, Tween 40, Tween 60, and Tween 80 were acquired from Merck, Darmstadt, Germany. Triton X-100 was obtained from Daejung Chemicals, Korea. Sodium hydroxide, glacial acetic acid, and potassium dihydrogen phosphate were obtained from Daejung Chemicals, Korea. Dimethyl sulfoxide (DMSO) and 4-bromophenylboronic acid were purchased from Merck, Darmstadt, Germany.

\subsection{Solubility Study}

The solubility of pitavastatin in different oils, surfactants, and co-surfactants was determined using a cyclomixer. Four milligrams of drug were added to $3 \mathrm{~mL}$ of each surfactant, co-surfactant, and essential oil. The mixture containing the drug was mixed by a cyclomixer for $24 \mathrm{~h}$ at $25^{\circ} \mathrm{C}$ with $2000 \mathrm{rpm}$. The sample containing the drug was then removed from the mixer and centrifuged at $9000 \mathrm{rpm}$ for $10 \mathrm{~min}$ to remove the amount of undissolved drug. The supernatant solution was then obtained from the mixture and passed through a $0.45 \mu \mathrm{m}$ Millipore membrane filter and diluted with dimethyl sulfoxide. The amount of pitavastatin in the mixture was determined using a UV spectrophotometer at $245 \mathrm{~nm}$ [13]. The experiment was repeated in triplicate.

\subsection{Construction of the Pseudo-Ternary Phase Diagram}

The pseudo-ternary phase diagram was constructed using oils, surfactants, and co-surfactants. Based on solubility studies of pitavastatin, the oils, surfactants, and cosurfactants were selected. With the concentration of oil (20-60\%), surfactant $(30-80 \%)$, and co-surfactant $(0-40 \%)$, a number of self-emulsifying series were prepared at $25^{\circ} \mathrm{C}$. Oils, surfactants, and co-surfactants mixtures with different concentrations were prepared in order to determine the self-emulsifying region. In the absence of pitavastatin, a pseudo-ternary phase diagram was constructed using $\mathrm{CHEMIX}^{\circledR}$ software $[14,15]$. All observations were reported and repeated in triplicate.

\subsection{Preparation of the Pitavastatin SNEDDS}

After identifying the self-emulsifying region, the different ratios of oils, surfactants, and co-surfactants for the SNEDDS were selected for the incorporation of pitavastatin. Four milligrams of pitavastatin were weighed and mixed with cinnamon oil followed by the addition of Tween 80 and PEG 400 as shown in Table 1 [16]. After, the preparation was placed in a sonicator to obtain a clear solution. The prepared SNEDDS was then stored for further studies.

Table 1. Formulations for SNEDDS of pitavastatin.

\begin{tabular}{ccccc}
\hline Formulation Code & Pitavastatin $(\mathbf{m g})$ & Essential Oils (\%) & Tween 80 (\%) & PEG 400 (\%) \\
\hline SPC1 & 4 & 30 & 60 & 10 \\
\hline SPC2 & 4 & 50 & 30 & 20 \\
\hline SPC3 & 4 & 40 & 40 & 20 \\
\hline SPT1 & 4 & 30 & 60 & 10 \\
\hline SPT2 & 4 & 50 & 30 & 20 \\
\hline SPT3 & 4 & 40 & 40 & 20 \\
\hline SPS1 & 4 & 30 & 60 & 10 \\
\hline SPS2 & 4 & 50 & 30 & 20 \\
\hline SPS3 & 4 & 40 & 40 & 20 \\
\hline
\end{tabular}


SPC1, 2, and 3 were SNEDDS of pitavastatin containing cinnamon oil; SPT1, 2, and 3 were SNEDDS of pitavastatin containing tea tree oil; and SPS1, 2, and 3 were SNEDDS of pitavastatin containing sesame oil.

\subsection{Characterization of the SNEDDS}

\subsubsection{Self-Emulsification Time}

The time taken by the pre-concentrate to form a homogeneous mixture after which the SNEDDS visually disappears is known as the self-emulsification time. The selfemulsification times were determined by a dissolution apparatus (USP Apparatus II) with a paddle speed of $100 \mathrm{rpm}$ at $37 \pm 5{ }^{\circ} \mathrm{C}$. Two microliters of the prepared SNEDDS were added dropwise to the medium (i.e., $900 \mathrm{~mL}$ of phosphate buffer) and the time until disappearance was calculated [17].

\subsubsection{Droplet Size Determination}

The average droplet size was investigated by PCM (phase contrast microscope). For this purpose, $2 \mathrm{~mL}$ of the prepared SNEDDS were diluted 50, 100, and 500 times with water and phosphate buffer with $\mathrm{pH} 1.2,3.0$, and 6.8, and the effect of the dispersion medium and volume of the medium on the droplet size was comparatively studied [18].

\subsubsection{Particle Size Analysis}

The average particle size of the prepared SNEDDS was investigated using a Malvern Zeta Sizer Nano Series ZS90. The polydispersity index indicates the uniformity of the particle diameter, and it may be used to determine the nanoemulsion's size distribution. The sensitivity range of the Malvern Zeta Sizer was in between the range of 10 and $5000 \mathrm{~nm}$. The temperature, while performing all these parameters, was maintained at $25^{\circ} \mathrm{C}$ with an angle of $90^{\circ}$ [19].

\subsubsection{Zeta Potential Analysis}

The stability of the nanoemulsion depends on the surface charge. The zeta potential of the prepared SNEDDS was determined using the Malvern Zeta Sizer Nano Series ZS90. Before the analysis, the sample was diluted with distilled water in the ratio of 1:100 $(v / v)$. The experiment was repeated in triplicate [20].

\subsubsection{Fourier Transform Infrared Spectroscopy (FTIR)}

The FTIR spectra of pitavastatin, cinnamon oil, Tween 80, PEG 400, and unloaded and loaded drug formulations were analyzed by an FTIR spectrophotometer (Bruker Alpha, Germany) with a wavelength range of $400-4000 \mathrm{~cm}^{-1}$, and each sample was tested at 10 scans within the wavelength range.

\subsubsection{Differential Scanning Calorimetry (DSC)}

For DSC, $5 \pm 0.5 \mathrm{mg}$ samples of pitavastatin, cinnamon oil, Tween 80, PEG 400, and unloaded and loaded drug formulations were placed in aluminum crucibles and heated from 50 to $400{ }^{\circ} \mathrm{C}$ at a $5{ }^{\circ} \mathrm{C} / \mathrm{min}$ heating rate under a stream of nitrogen gas flow at $40 \mathrm{~mL} / \mathrm{min}$ using a differential scanning calorimeter (DSC-60, Shimadzu, Germany).

\subsubsection{Thermogravimetric Analysis (TGA)}

For TGA, $10 \pm 0.5 \mathrm{mg}$ sample of pitavastatin, cinnamon oil, Tween 80, PEG 400, and unloaded and loaded drug formulations were placed in aluminum crucibles and heated from 50 to $400{ }^{\circ} \mathrm{C}$ at a $10{ }^{\circ} \mathrm{C} / \mathrm{min}$ heating rate under a stream of nitrogen gas flow at $40 \mathrm{~mL} / \mathrm{min}$. The heating temperature was considered to be the function of the percentage weight loss. 


\subsection{In Vitro Dissolution Studies}

The in vitro drug release studies were performed using the dialysis bag method using a USP Apparatus II. The prepared SNEDDS of pitavastatin were added to the dialysis bag, which was then sealed. The sealed bag added in $900 \mathrm{~mL}$ of dissolution medium (phosphate buffer) with a $\mathrm{pH}$ of 6.8 at $37^{\circ} \mathrm{C}$. The speed of the paddle was maintained at $100 \mathrm{rpm}$ [21]. With predetermined time intervals, $5 \mathrm{~mL}$ of sample was collected, and $5 \mathrm{~mL}$ buffer was added to maintain the sink condition. The release of pitavastatin from the prepared SNEDDS was compared with marketed formulations. A UV spectrophotometer determined the presence of drug content from the sample. All observations were reported and repeated in triplicate.

\subsection{Kinetics of Pitavastatin Release}

To obtain the release kinetics and evaluate the mechanism of pitavastatin release, the data on in vitro pitavastatin release from the SNEDDS were fitted to five mainly applied mathematical models (i.e., Korsmeyer-Peppas model, Hixon-Crowel model, Higuchi model, first order, and zero order) for the evaluation of the release kinetics of pitavastatin from the prepared SNEDDS.

\subsection{Ex Vivo Permeation Studies}

Adult Male Wistar rats, with a weight of 200-250 g, were kept in a room with a constant room temperature of $25{ }^{\circ} \mathrm{C}$ and relative humidity of $55 \%$ with free access to a normal meal and water. The rats were starved overnight but given water only before the experiment. Animals were sacrificed by dislocating their spines. By cutting between the lower end of the ileum and the upper end of the duodenum and removing the mesentery, the small intestine was directly separated followed by sacrifice. Using a syringe with a blunt end, the small intestine was thoroughly cleaned out with KRPB (Kreb's Ringer phosphate buffer) solution. The intestinal sacs were cleaned and split into $6 \mathrm{~cm}$ pieces. One microliter of KPRB was used to distribute the selected SNEDDS. At the same drug concentration, a suspension of marketed pitavastatin tablet and pitavastatin powder (control) was also dispersed in $1 \mathrm{~mL}$ of KRPB. Six sacs were filled with the SNEDDS and TC solution (equal to $4 \mathrm{mg}$ of the drug) using a blunt needle, while the other six sacs were filled with an equivalent amount of tablet and powder suspensions. A thread was used to tie the two sides of the intestine. Each sac was put into a glass test tube with $10 \mathrm{~mL}$ of KRPB solution. In a shaking water bath spinning at $100 \mathrm{rpm}$, the entire system was kept at $37^{\circ} \mathrm{C}$ and aerated with a laboratory aerator. Over a period of $2 \mathrm{~h}$, samples were removed from the outside of the sac and the medium was completely replaced with fresh medium. HPLC was used to evaluate the samples [22]. Pitavastatin permeability was determined by charting the total amount of medication penetrated through the sac verses time. The pitavastatin apparent permeability coefficient (PAAP) was derived using the following equation:

$$
P A P P\left(\frac{c m}{s e c}\right)=\frac{\frac{d Q}{d t}}{\frac{A}{C_{0}}}
$$

where $d Q / d t$ is the drug permeation rate from the membrane, a is the cross-sectional area of the tissues, and $C_{0}$ is the initial pitavastatin concentration in the donor compartment at $t_{0}$.

\subsection{In Vitro Lipolysis Tests}

In the lipolysis test [23], the selected SNEDDS formulations were distributed in $9 \mathrm{~mL}$ of digestion buffer under fed ( $\mathrm{pH} 5.0,144 \mathrm{mM}$ glacial acetic acid, $101 \mathrm{mM} \mathrm{NaOH}$, and $203 \mathrm{Mm} \mathrm{NaCl}$ ) and fasted ( $\mathrm{pH}$ 6.5, $28.6 \mathrm{mM} \mathrm{NaH}_{2} \mathrm{PO}_{4} . \mathrm{H}_{2} \mathrm{O}, 10.5 \mathrm{mM} \mathrm{NaOH}$, and $105.9 \mathrm{mM}$ $\mathrm{NaCl}$ ) conditions. In the digestion mixture, SIF powder comprising lecithin (phospholipid) and taurocholate (bile salt) in 1:4 molar ratios (the ratio secreted in bile) was incorporated. Prior to enzyme addition, the lipid formulations in the mixed micellar solutions were 
emulsified in the thermostatic jacketed glass reaction vessel by spinning constantly for $10 \mathrm{~min}$. Trials were carried out at $37^{\circ} \mathrm{C}$, and to start the process of lipolysis, $1 \mathrm{~mL}$ of pancreatin extract containing 800 units of tributyrin of pancreatic lipase was added. Using a $\mathrm{pH}$-stat titration machine that kept the $\mathrm{pH}$ constant at 6.8 , lipolysis was allowed to continue for $30 \mathrm{~min}$. All of the formulations had their fatty acids generated during lipolysis titrated with $0.2 \mathrm{M} \mathrm{NaOH}$. Three samples of $2 \mathrm{~mL}$ digestion solution were transferred into polyallomer centrifuge tubes at the end of each digestion experiment, and $20 \mu \mathrm{L}$ of 4-bromophenylboronic acid was added to each sample to inhibit further lipolysis. To separate the different digestion phases, the samples were ultra-centrifuged at $8000 \mathrm{rpm}$ for $50 \mathrm{~min}$ at $4{ }^{\circ} \mathrm{C}$ using an SW-60 swinging bucket rotor. The formulation digests were separated into two phases after ultracentrifugation: aqueous and precipitated pellet. HPLC was used to determine the drug content of the samples obtained from each of the separated phases.

\subsection{RBC Lysis Test}

An RBC lysis test was performed for the evaluation of in vitro acute toxicity of the pitavastatin-loaded SNEDDS. Briefly, blood from a healthy human was placed in an anticoagulant solution and centrifuged at $1000 \times g$ for $15 \mathrm{~min}$ at $4{ }^{\circ} \mathrm{C}$. The buffy coat and plasma-containing supernatant was discarded. The RBC-containing pellet was washed and diluted in isotonic buffer $(150 \mathrm{mM} \mathrm{NaCl}$ and $10 \mathrm{mM}$ phosphate buffer) to obtain a $50 \%$ hematocrit. The RBC suspension of aliquots were treated for $1 \mathrm{~h}$ at $37^{\circ} \mathrm{C}$ with $4 \mathrm{mg} / \mathrm{mL}$ of each tested formulation. The aliquots were centrifuged at $1500 \times g$ for $1 \mathrm{~h}$, after which the supernatant was analyzed for released hemoglobin with the help of UV Visible spectroscopy at $576 \mathrm{~nm}$ [23].

\subsection{Effect of the SNEDDS Formulations on Lipid Profile}

For this purpose, 24 rabbits were selected and divided into four groups and given favorable conditions. All groups had full access to diet and water. To induce hypercholesteremia, $100 \mathrm{mg} / \mathrm{kg} /$ day of cholesterol was administered to the rabbits for 15 days. The fasting cholesterol level was evaluated to ensure the induction of hypercholesteremia in rabbits. A parallel study design method was used to determine the effect of pitavastatincontaining SNEEDS on the rabbits' lipid profile [24]. Group I was the control group, group II was the disease control, group III was the standard (treatment with marketed formulation Pitalo $^{\circledR}$ ), and group IV received an SNEDDS of pitavastatin for five weeks. Blood samples were collected and analyzed.

\subsection{Stability Studies}

The stability study was conducted by placing the SPC3 formulation in tightly sealed bottles for 90 days at a $45 \pm 2.0{ }^{\circ} \mathrm{C}$ temperature and $75 \pm 5.0 \%$ humidity. The samples were withdrawn at $0,30,60$, and 90 days and analyzed for color, self-emulsification time, particle size, and zeta potential.

\subsection{Cytotoxicity Studies}

The Caco-2 model was used to evaluate the toxicity of the SNEDDS in the MTT assay for cell viability study. The ATCC (American Type Culture Collection) was the main source of the Caco-2 cell line. Eagles' MEM (minimum essential medium) along with $20 \%$ FBS (fetal bovine serum) were mainly used for the cultivation of the Caco-2 cell in 96-well plates. Prior to treatment, all excipients (essential oil, Tween 80, and PEG 400), drug (pitavastatin), and formulations were diluted in DMEM (Dulbecco's modified Eagle's medium) with 0.5\% DMSO. DMEM without FBS was used for incubation with cells after treatment with $200 \mu \mathrm{g} / \mathrm{mL}$ SPC3 and blank formulations and with the same concentration of excipients used in the SPC3 formulation. Following incubation, the samples were collected at a predetermined time, and the collected sample was washed with PBS. After, a solution of MTT was added to the medium having no FBS, and this preparation was incubated for 
$1 \mathrm{~h}$ and the supernatant removed and dissolved in DMSO. At a wavelength of $570 \mathrm{~nm}$, the absorbance of the prepared solution was noted. The following equation was used to evaluate the percentage of cell viability [25]:

$$
\text { Cell viability }(\%)=\frac{A s}{A d} \times 100
$$

where $A_{s}$ is absorbance after treatment with the sample dispersion, and $A_{d}$ is the absorbance after treatment with DMEM.

\subsection{Pharmacokinetics of Pitavastatin}

Two groups of six albino rats, a test group, and a control group, weighing between 0.3 and $0.5 \mathrm{~kg}$, were selected for the pharmacokinetic studies. The pharmacokinetics evaluation was evaluated with the approval of the Ethical Committee for the Utilization of Laboratory Animals, Government College, University Faisalabad, Punjab, Pakistan. The ICH (International Council for Harmonization) rules and regulations were abided for the handling of albino rats while performing pharmacokinetic evaluation. The albino rats had full access to water and diet with a circadian cycle of light and dark. The temperature was maintained at $25 \pm 5^{\circ} \mathrm{C}$ for the entire period. The albino rats were abstained for $24 \mathrm{~h}$ prior to beginning the pharmacokinetic analysis, yet they were permitted free access to water. A feeding tube was used to administer the prepared SNEDDS and suspension of pitavastatin to the groups. The pitavastatin suspension and the SPC3 formulation were prepared in a $0.25 \%$ carboxymethyl cellulose solution and administered orally at a dose of $10 \mathrm{mg} / \mathrm{kg}$. The volume administered was $5 \mathrm{~mL}$. All rats were labeled accurately and confined in a wooden box while performing the collection of the samples. At a predetermined time period, a total of $0.25 \mathrm{~mL}$ blood was extracted from the tail of the rat and shifted to a centrifugation tube. The tube was centrifuged at $6000 \mathrm{rpm}$ for $10 \mathrm{~min}$ and the plasma collected and stored at $-20{ }^{\circ} \mathrm{C}$. A liquid-liquid extraction method was used to obtain the pitavastatin from the plasma. The obtained sample was then reconstituted with $100 \mu \mathrm{L}$ of the mobile phase and an HPLC-UV spectrophotometer was used to evaluate the pharmacokinetics of the prepared SNEDDS [26].

\subsubsection{Data Analysis}

The concentrations of pitavastatin in the SNEDDS and in the suspension of the pitavastatin were evaluated by calibration curves, which were constructed using Microsoft Excel 2007. Kinetica R version 4.1.0 (Thermo Electron Corporation, USA) was used to evaluate the pharmacokinetics parameter. Equation (3) was used for the determination of the maximum concentration of the drug in plasma, $C_{\max } \mathrm{ng} / \mathrm{mL}$. Equation (4) was used to determine the time to reach the peak plasma concentration in blood, $t_{\max }$. The area under the plasma concentration from the time curve to time $\mathrm{t}, A U C_{0-t} \mathrm{ng} / \mathrm{mL} \mathrm{h}$, was determined using Equation (5). In addition, Equation (5) was used for the area under the plasma concentration from the time curve to infinity $\left(A U C_{0-\infty}, \mathrm{ng} / \mathrm{mL} . \mathrm{h}\right)$. Equation (6) was used for the determination of the area under the maximum concentration (AUMC). Clearance, $\mathrm{Cl} \mathrm{h}{ }^{-1}$ half-life, $\mathrm{kel} \mathrm{h}^{-1}$, and mean residence time (MRT) were evaluated using Equation (7).

$$
\begin{gathered}
C_{\text {max }}=\frac{F X_{0}}{V_{d}} \times e^{-k t_{\text {max }}} \\
t_{\text {max }}=2.303 \log \left(K_{a} / K_{e}\right)\left(K_{a}-K_{e}\right) \\
A U C_{0-t}=\sum_{1}^{n} \frac{C_{i}+C_{i}+1}{2} \cdot \Delta t \\
A U M C_{0-t}=\sum_{1}^{n} \frac{t_{i}\left(C_{i}+C_{i}+1\right)}{2} \cdot \Delta t
\end{gathered}
$$




$$
M R T=\frac{A U M C}{A U C}
$$

where $F$ is the dose fraction, $V_{d}$ is the volume of distribution, $K_{a}$ is the absorption rate constant, $K_{e}$ is the elimination rate constant, $\Delta t\left(t_{2}-t_{1}\right)$ is the time interval, $C_{i}$ is the Initial amount, and $C_{i}+1$ is the final amount.

\subsubsection{Statistical Analysis}

SPSS (SPSS Inc., Chicago, IL, USA) version 17 was used to evaluate the pharmacokinetic parameters statistically. The Student's $t$-test was used to compare the results between the test group and control group.

\section{Results and Discussion}

\subsection{Solubility Study}

The solubility of pitavastatin in different excipients used in the formulation of the SNEDDS was evaluated in order to generate a stable region for self-emulsification in a ternary phase diagram with a large border size and a nano droplet size [27]. The pitavastatin solubility in various excipients is depicted in Figure 1A-C. Pitavastatin was found to have the highest solubility in cinnamon oil $(3.9 \mathrm{mg} / \mathrm{mL})$ and olive oil $(3.2 \mathrm{mg} / \mathrm{mL})$ and the lowest solubility in virgin coconut oil. Because of their propensity to solubilize pitavastatin, cinnamon oil, olive oil, ginger oil and castor oil were chosen as oil phases for future analysis. Tween $80(3.8 \mathrm{mg} / \mathrm{mL})$ and Tween $20(3.32 \mathrm{mg} / \mathrm{mL})$ had the maximum solubility of Pitavastatin among the several surfactants tested. Tween 80 , a non-ionic surfactant, was used as a surfactant for this study, since it has been shown to improve medication absorption. PEG $400(3.56 \mathrm{mg} / \mathrm{mL})$ and PEG $200(3.00 \mathrm{mg} / \mathrm{mL})$ were shown to have good solubilization properties for pitavastatin. Based on their statistical significance, the abovementioned excipients were chosen for future studies.
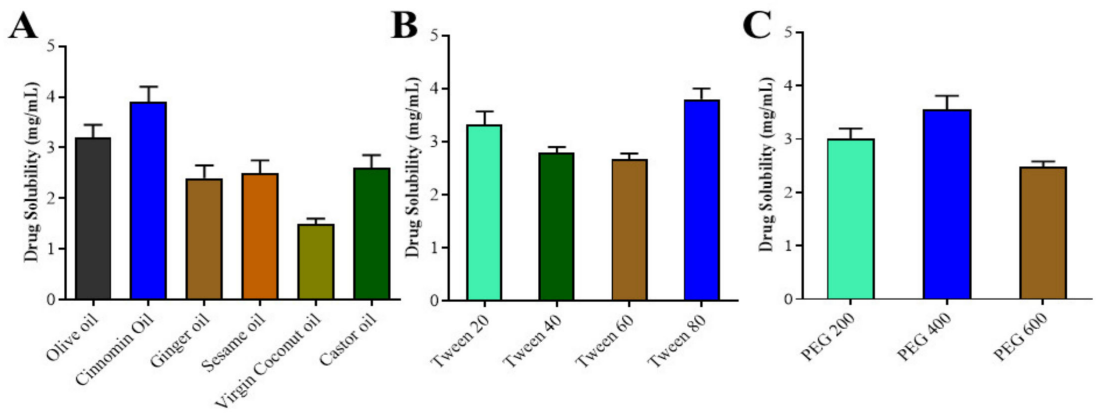

D

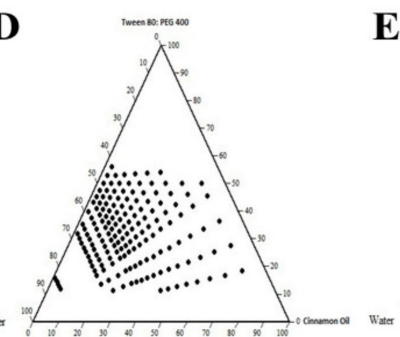

$\mathbf{E}$

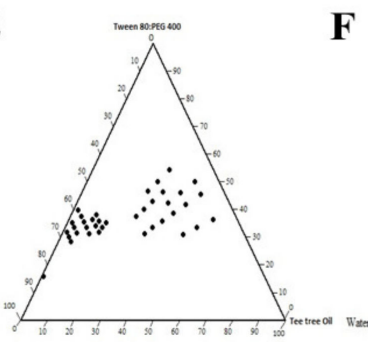

$\mathbf{F}$

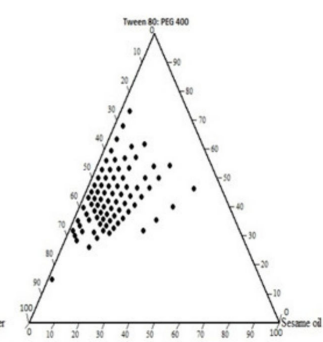

Figure 1. Solubility studies of pitavastatin in oils (A), surfactants (B), and co-surfactants (C); pseudo ternary phase diagram in cinnamon oil (D), tea tree oil (E) and sesame oil (F).

\subsection{Pseudo Ternary Phase Diagram}

In the absence of pitavastatin, pseudo ternary phase diagrams, as shown in Figure 1D-F, were constructed to find the region of self-emulsification and optimize the percentages of a variety of excipients for the optimal formulation. Solubility analysis showed that olive oil, cinnamon oil, ginger oil, and castor oil had the maximum capability to solubilize the drug therefore these oils were used as oil phases. For generating multiple phase diagrams 
in order to determine the optimal self-emulsification region, PEG 400 and Tween 80 were used as co surfactants and surfactants, respectively. Turbid emulsions were produced when surfactant concentrations were $40-50 \%$, which was significant. As the amount of cosurfactant in the SNEDDS was raised, the potential to spontaneously generate an emulsion inside self-emulsification zone improved. For self-emulsification, the minimal ratio of Smix was 45-75\%. The effectiveness of self-emulsification of the SNEDDS formulation was improved when the Smix ratio (mixture of surfactant and co-surfactant) was greater than $60 \%$. In order to generate a phase diagram, the effect of surfactants and co-surfactants on droplet size were assessed, and it was observed that droplet size was lowered from 270 to $75 \mathrm{~nm}$ as the surfactant concentration was increased from 30\% to $60 \%$. However, increasing the surfactant concentration to $70 \%$ caused the larger mean droplet size. The best self-emulsifying properties were discovered in nine different formulations [28].

\subsection{Characterization of SNEDDS}

\subsubsection{Self-Emulsification Time}

The emulsification time was the most important indicator for the efficiency of selfemulsification. SNEDSS should disperse quickly and completely. Prepared SNEDDS formulation SPC3 showed a very less emulsification time, i.e., less than 1 min when compared to other prepared formulations.

\subsubsection{Droplet Size Analysis}

The distribution of droplet size is one of the most significant emulsion characteristics for stability assessment and a key step in improving the bioavailability of drugs [29]. Prepared formulations SPC1, SPC2, and SPC3 were selected for droplet size analysis; the smaller the particle size leads to an enhanced the surface area, thus improving the absorption of the drug. The droplet size of all formulations was less than $200 \mathrm{~nm}$. Among these formulations, SPC3 has the smallest droplet size, i.e., $109 \pm 0.51 \mathrm{~nm}$.

\subsubsection{Particle Size Distribution}

The particle size distribution was assessed using the prepared formulations that had been chosen. Formulation having a smaller particle size leads towards rapid absorption and, thus, improved bioavailability [30]. From the selected formulations, SPC3 showed $104 \pm 1.50 \mathrm{~nm}$ particle sizes as shown in Table 2A Figure 2A and the polydispersity index (PDI) of the SPC3 formulations was 0.198. The results indicated that when the oil concentration in the formulation increased, the particle size and PDI increased, and the zeta potential value changed from more negative to less negative as shown in Table 2.

Table 2. Particle size and zeta potential of developed formulations.

\begin{tabular}{cccc}
\hline Formulation Code & Particle Size (nm) & PDI & Zeta Potential \\
\hline SPC1 & $112 \pm 2.02$ & 0.208 & -16 \\
\hline SPC2 & $116 \pm 1.31$ & 0.338 & -13 \\
\hline SPC3 & $104 \pm 1.50$ & 0.198 & -29 \\
\hline SPT1 & $124 \pm 2.12$ & 0.372 & -17 \\
\hline SPT2 & $119 \pm 2.10$ & 0.467 & -15 \\
\hline SPT3 & $111 \pm 1.27$ & 0.301 & -25 \\
\hline SPS1 & $114 \pm 2.05$ & 0.408 & -27 \\
\hline SPS2 & $121 \pm 1.10$ & 0.467 & -17 \\
\hline SPS3 & $108 \pm 1.01$ & 0.351 & -20 \\
\hline
\end{tabular}



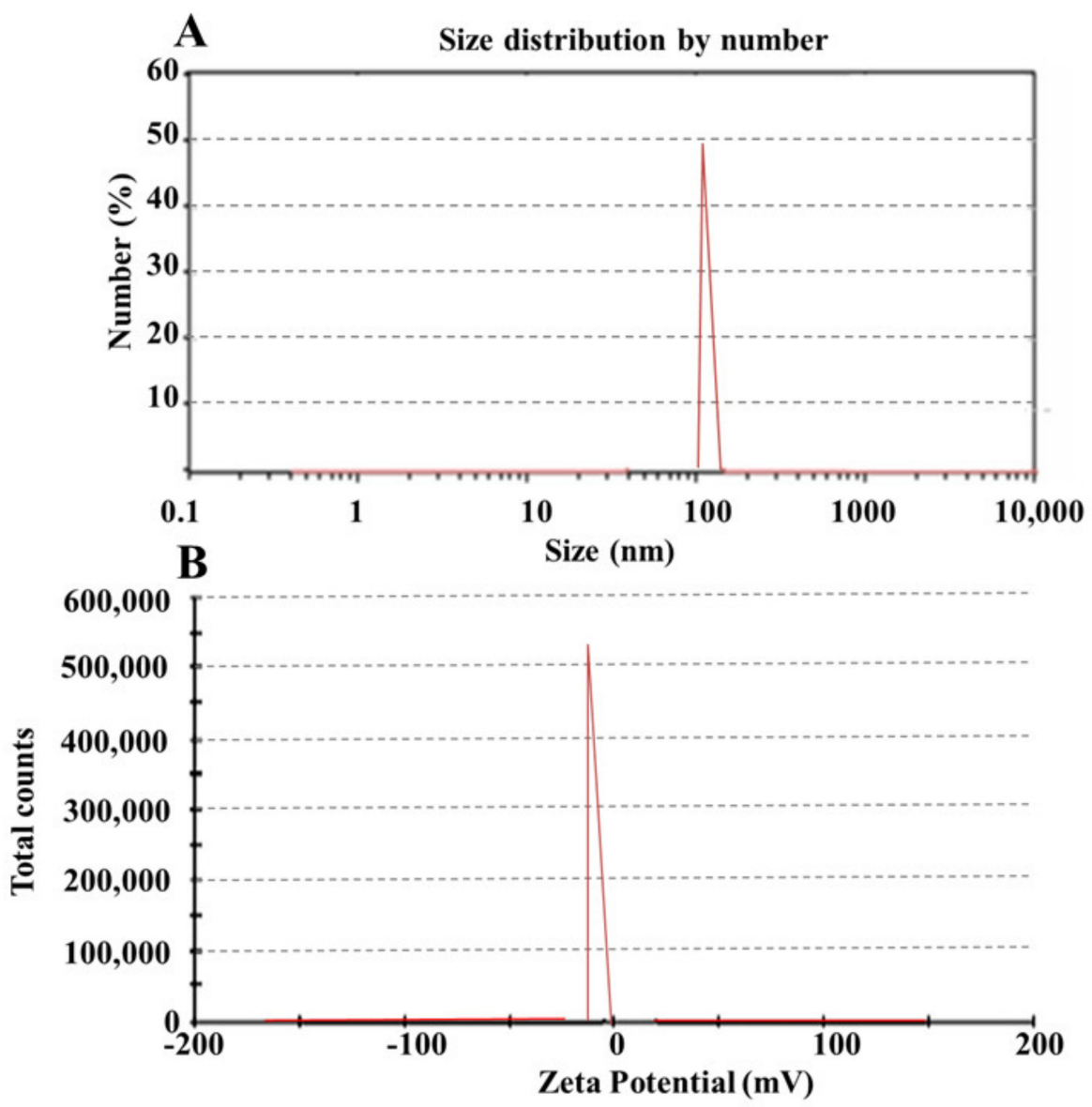

Figure 2. Zeta sizer (A) and zeta potential (B) of the SPC3 formulation.

\subsubsection{Zeta Potential}

The prepared SNEDDS with the code names SPC1, SPC2, and SPC3 were selected for zeta potential analysis. The stability of the formulation depends on the zeta potential as it opposes aggregation [30]. Zeta potentials of the prepared formulation SPC1, SPC2, and SPC 3 were $-13,-16$, and -29 as shown in Figure 2B. From these formulations SPC3 was the most stable one. A high negative charge on prepared formulation depends on the presence of free fatty acids. The value of zeta potential $\pm 30 \mathrm{mV}$ was enough for the system's stability.

\subsubsection{Fourier Transforms Infrared Spectroscopy (FTIR)}

The pitavastatin showed a peak of hydroxyl group at $3352 \mathrm{~cm}^{-1}$. The peak at 2912, 1510, and $752 \mathrm{~cm}^{-1}$ indicated the presence of $\mathrm{C}-\mathrm{H}$, carboxyl and $\mathrm{C}-\mathrm{F}$ groups [31] as shown in Figure 3. The cinnamon oil showed peaks at 3712, 2904, 1639, 1487, 1201, and $1072 \mathrm{~cm}^{-1}$ were due to the amine and phenols, alkanes, ketone, ester and alkenes, nitro group, ether and esters [32] respectively. The spectra of PEG 400 showed O-H stretching at $3299 \mathrm{~cm}^{-1}$, $\mathrm{C}-\mathrm{H}$ stretching at $2819 \mathrm{~cm}^{-1}, \mathrm{C}-\mathrm{H}$ bending at $1415 \mathrm{~cm}^{-1}$, and $\mathrm{C}-\mathrm{O}-\mathrm{H}$ stretching was observed at $1069 \mathrm{~cm}^{-1}$ [33]. Tween 80 showed a stretching vibration of the hydroxyl group at $3416 \mathrm{~cm}^{-1}$. The asymmetric and symmetric stretching bonds of Tween 80 were observed at 2917 and $2756 \mathrm{~cm}^{-1}$, respectively, as shown in Figure 3. The stretching of $\mathrm{C}=\mathrm{O}$ ester group was shown at $1726 \mathrm{~cm}^{-1}$ [34]. The drug-loaded formulation showed the peaks of drug, surfactants, and co-surfactants that indicated the chemical compatibility of the SNEDDS formulation. 


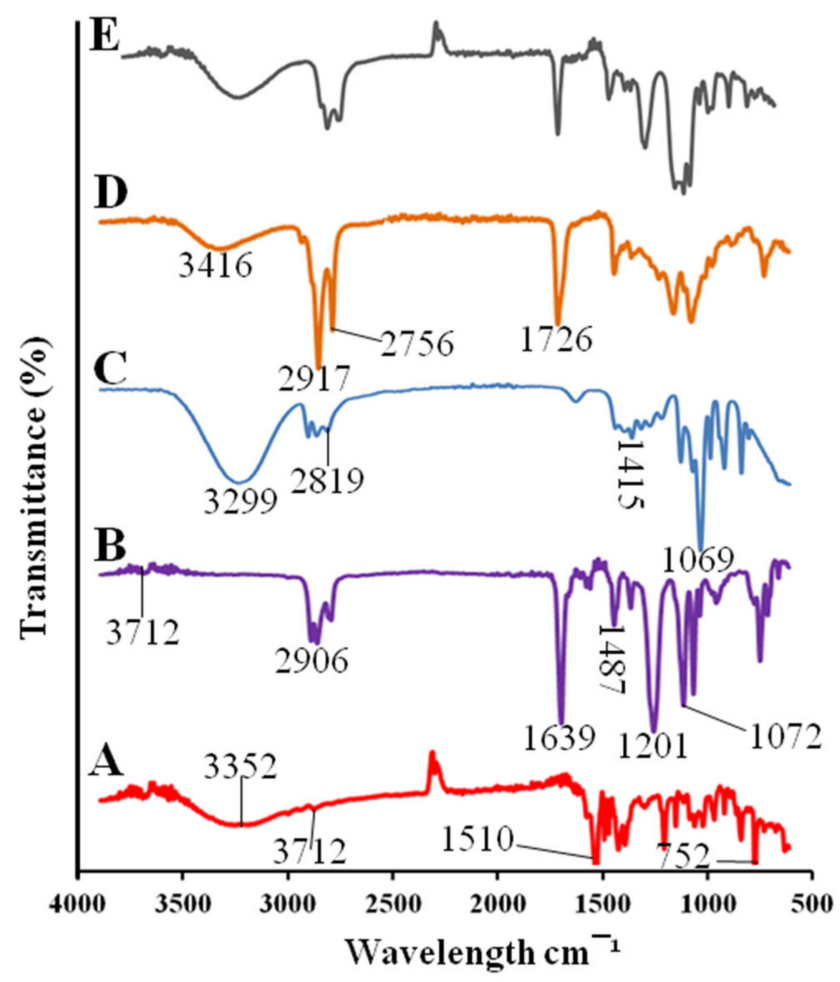

Figure 3. FTIR spectra of pitavastatin (A), cinnamon oil (B), PEG 400 (C), Tween 80 (D), drug-loaded SPC3 formulation (E).

\subsubsection{Differential Scanning Calorimetry (DSC)}

Pitavastatin drug showed an endothermic peak at $140{ }^{\circ} \mathrm{C}$ and an exothermic peak at $220^{\circ} \mathrm{C}$ as shown in Figure $4 \mathrm{~A}$. Cinnamon oil showed at $50{ }^{\circ} \mathrm{C}$ an exothermic peak and two endothermic peaks at 140 and at $290^{\circ} \mathrm{C}$. PEG 400 showed an endothermic peak at $42^{\circ} \mathrm{C}$ and Tween 80 showed an endothermic peak at $108^{\circ} \mathrm{C}$. Our prepared SNEDDS formulation showed two endothermic peaks at 48 and $106{ }^{\circ} \mathrm{C}$, and there was no peak of pitavastatin which indicates that drug was uniformly distributed in prepared SNEDDS formulation [35].
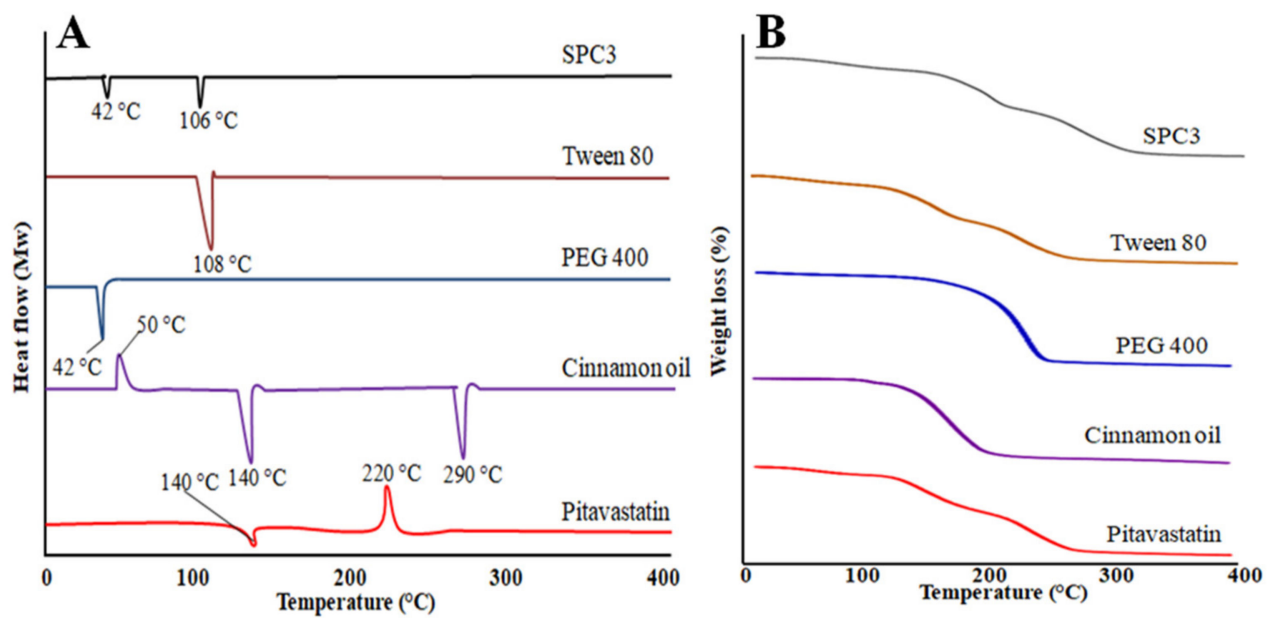

Figure 4. DSC thermograms (A) and TGA (B) curves of pitavastatin, cinnamon oil, PEG 400, Tween 80 , and the SPC3 formulation.

\subsubsection{Thermogravimetric Analysis (TGA)}

Thermogravimetric analysis was used to evaluate the thermal stability of prepared SNEDDS formulation, cinnamon oil, PEG 400, Tween 80 and pitavastatin drug. Pitavastatin 
drug showed a weight loss starts from 100 to $300^{\circ} \mathrm{C}$ and it was observed that after $300{ }^{\circ} \mathrm{C}$ there was no weight loss observed as shown in Figure 4B. Cinnamon oil showed a rapid weight loss starting from 100 to $200{ }^{\circ} \mathrm{C}$. PEG 400 showed a speedy weight loss starting from 181 to $284{ }^{\circ} \mathrm{C}$. Tween 80 showed a gradual weight loss starting from 141 to $296^{\circ} \mathrm{C}$. The prepared SPC3 SNEDDS formulation showed a gradual weight loss starting from 100 to $300{ }^{\circ} \mathrm{C}$ indicated the stability of SNEDDS [35,36].

\subsection{In Vitro Drug Release Study and Release Kinetics}

Using $900 \mathrm{~mL}$ of dissolution medium with a $\mathrm{pH}$ of 6.8 at $37^{\circ} \mathrm{C}$, the in vitro drug release study was performed. The release pattern of pitavastatin from the SNEDDS showed that maximum release of the drug was observed with SPC3 formulation after $12 \mathrm{~h}$ as shown in Figure 5A. This could be due to the proper oil and surfactant composition of the system. The formulation of SPC1 showed a lower release of around $89.78 \pm 0.88 \%$ of the drug, which may be due to a higher proportion of oil resulting in a larger droplet size and smaller surface area exposed to the medium [23]. It is evident from the data that the release rate of pitavastatin from the SNEDDS formulations was substantially higher than the commercially available drug formulation. The percentage release of pitavastatin from SPC3 was $98.5 \pm 2.5 \%$ after $12 \mathrm{~h}$, which was substantially higher than the marketed formulation, i.e., $55.45 \pm 1.55 \%$. Therefore, the in vitro findings reveal that the prepared SNEDDS formulation showed improved release of pitavastatin. The values of kinetics of pitavastatin release are shown in Table 3. The SNEDDS of pitavastatin showed the zero order kinetics with non-fickian diffusion release mechanism.
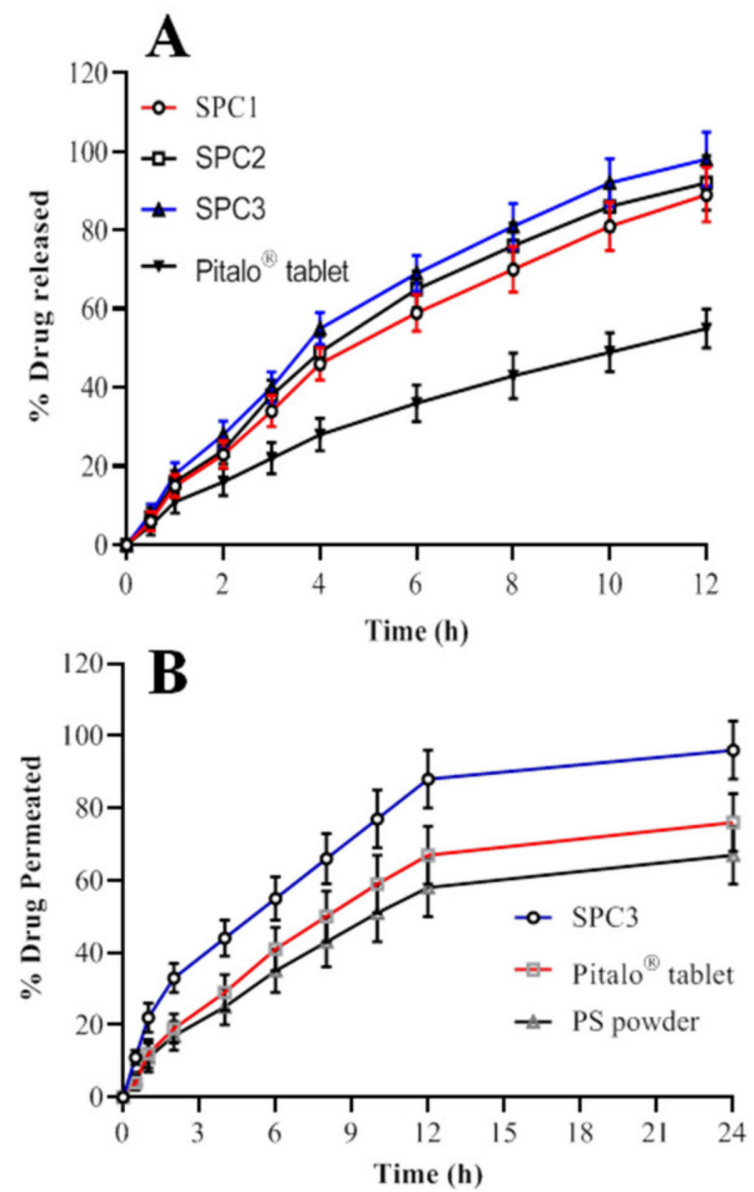

Figure 5. \%age drug release (A) and \%age drug permeated (B) of pitavastatin from the SNEDDS formulation. 
Table 3. Values of kinetics of the pitavastatin release.

\begin{tabular}{lcccccc}
\hline \multirow{2}{*}{ Code } & \multicolumn{2}{c}{ Korsemeyer-Peppas } & Hixon-Crowell & Higuchi & First-Order & Zero-Order \\
\cline { 2 - 7 } & $\boldsymbol{R}^{\mathbf{2}}$ & $\boldsymbol{n}$ & $\boldsymbol{R}^{\mathbf{2}}$ & $\boldsymbol{R}^{\mathbf{2}}$ & $\boldsymbol{R}^{\mathbf{2}}$ & $\boldsymbol{R}^{\mathbf{2}}$ \\
\hline SPC1 & 0.9980 & 0.829 & 0.9968 & 0.9140 & 0.9826 & 0.9939 \\
\hline SPC2 & 0.9974 & 0.885 & 0.9949 & 0.8942 & 0.9880 & 0.9917 \\
\hline SPC3 & 0.9982 & 0.789 & 0.9961 & 0.9280 & 0.9927 & 0.9995 \\
\hline SPT1 & 0.9940 & 0.706 & 0.9979 & 0.9506 & 0.9939 & 0.9995 \\
\hline SPT2 & 0.9902 & 0.661 & 0.9978 & 0.9607 & 0.9879 & 0.9997 \\
\hline SPT3 & 0.9898 & 0.681 & 0.9986 & 0.9540 & 0.9729 & 0.9817 \\
\hline SPS1 & 0.9938 & 0.671 & 0.9904 & 0.9613 & 0.9857 & 0.9913 \\
\hline SPS2 & 0.9971 & 0.700 & 0.9927 & 0.9561 & 0.9758 & 0.9903 \\
\hline SPS3 & 0.9985 & 0.657 & 0.9909 & 0.9706 & 0.9834 & 0.9979 \\
\hline
\end{tabular}

\subsection{Ex Vivo Permeation Studies}

The permeation studies were conducted to evaluate the in vitro release and prediction of in vivo absorption of Pitavastatin. The ex vivo intestinal permeation of pitavastatin from SNEDDS of SPC3 was evaluated and compared with pitavastatin powder (control) and commercialized tablet (Pitalo) by non-everted sac method [37] as shown in Figure 5B. The average plasma concentration of pitavastatin over a period of $24 \mathrm{hr}$ period is shown in Figure 5B. The optimized SNEDDS (SPC3) formulation had the highest capability to permeate through the intestine as compared to the pitavastatin powder and Pitalo ${ }^{\circledR}$. After $2 \mathrm{~h}$ the intestinal permeation of the optimized SPC3 SNEDDS reached $96 \%$, Pitalo ${ }^{\circledR} 76 \%$ and pitavastatin powder $67 \%$ as shown in Figure 5B. The drug is soluble in the permeation media and no solid particles were seen on the sac. The enhanced intestinal absorption of pitavastatin from SNEDDS formulation could be explained by number of ways. The quick permeation of pitavastatin inside the intestinal sac and quick diffusion could explain the high penetration. The enhanced drug absorption is because of the nano sized droplets of the emulsion in the region of intestine, which could improve the pitavastatin absorption, also nanoemulsion provide a greater surface area for drug penetration through intestine [22]. Furthermore, the SPC3 formulation have high drug solubility along with rapid self-emulsification may have aided pitavastatin absorption in the intestine. The bioenhancing capability of the surfactant (Tween 80) and co-surfactants (PEG 400) improves the permeability by disrupting cell membrane lipids [38]. In vitro drug release investigation showed a similar correlation.

\subsection{Lipolysis Test}

Digestion of the SNEDDS in the small intestine is important for the release of the incorporated drug. Digestion of SNEDDS in aqueous phase release a significant amount of drug as compared to pellet phase suggesting greater permeability of drug through intestine. The values of percentage of drug recovery were also adjusted. This test was carried out to verify the in vivo behavior of the SNEDDS. The SPC3 formulation was selected to check the digestion in fasted and fed conditions and results are shown in Figure 6A. Under fasting condition, the aqueous and pellet phase showed $62.45 \%$ and $13.23 \%$ digestion of the SPC 3 formulation and $12.39 \%$ and $83.74 \%$ digestion of the TC formulation. In the fasted condition, the total recovery of PS from SPC 3 and CO after $30 \mathrm{~min}$ was $74.34 \%$ and $89.17 \%$, respectively. In the fed condition, the aqueous and the pellet phase showed a $52.15 \%$ and $17.73 \%$ digestion of SPC 3 formulation and $28.19 \%$ and $67.24 \%$ digestion of TC formulation. In the fed condition, the total recovery of PS from SPC3 and CO after $30 \mathrm{~min}$ was $75.18 \%$ and $90.30 \%$, respectively. In the aqueous phase, the digestion of SPC 3 yielded a high amount of PS compared to the CO formulation. CO had greater solubility of PS in the pellet phase and retained a good quantity of PS [39,40]. The in vitro lipolysis test 
demonstrated the bio-relevance for the release and absorption of PS from the lipid-based SNEDDS formulation. In the lipolysis test, the quantity of drug is determined form the SNEDDS when the lipolysis reaction was completed.
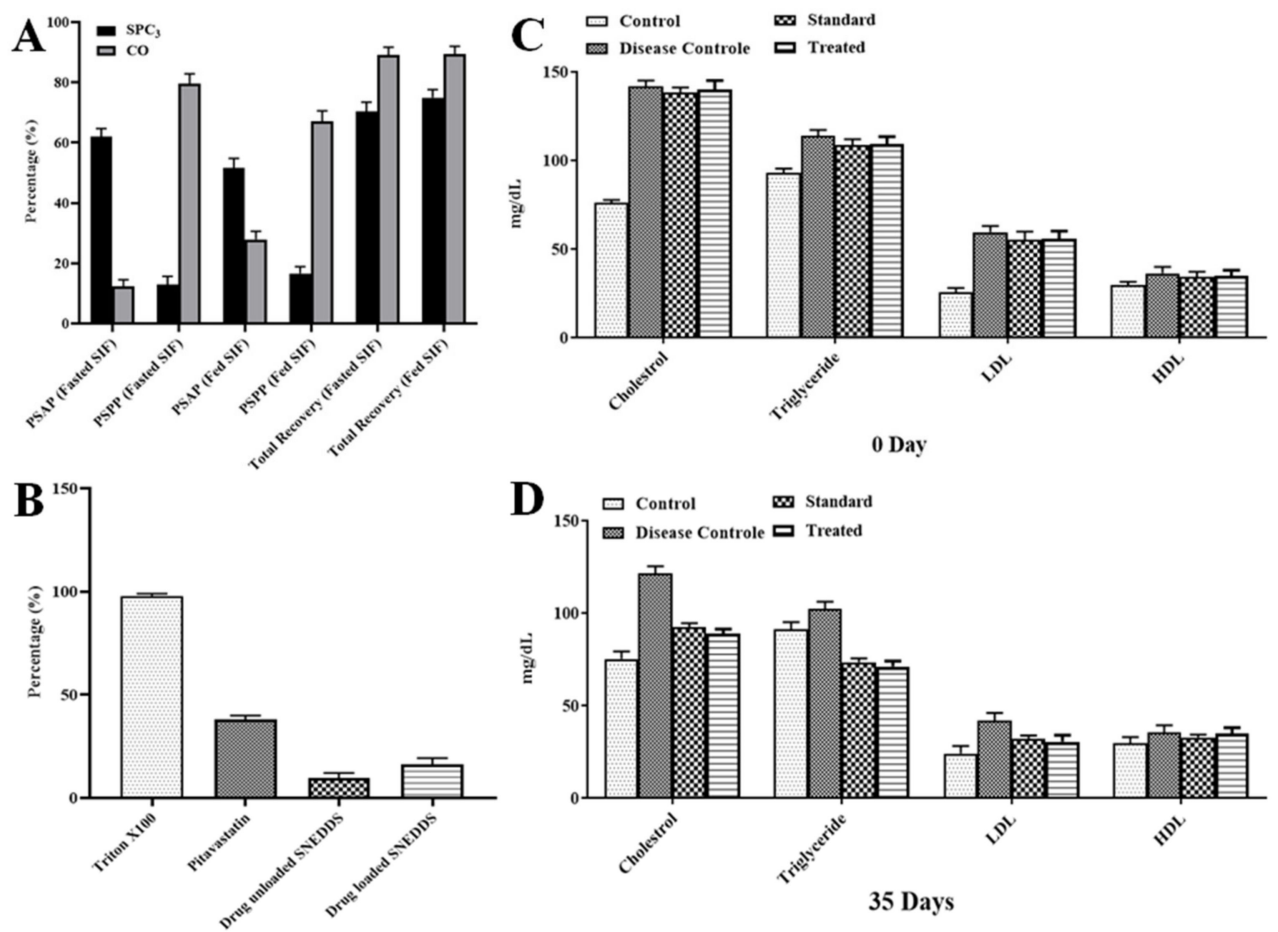

Figure 6. In vitro lipolysis (A), RBC lysis (B) and lipid profile of albino rats at 0 (C) and 35 days (D). CO, is cinnamon oil (pitavastatin in oil); PSAF, pitavastatin in aqueous phase; PSPP, pitavastatin in pellet phase; SIF, simulated intestinal fluid; LDL, low-density lipoprotein; HDL, high-density lipoprotein.

\subsection{RBC Lysis Test}

An in vitro RBC lysis test was performed to see if the SNEDDS formulation caused RBC toxicity. The use of Triton X-100 as a positive control resulted in $100 \%$ RBC lysis [23]. The RBC lysis caused by the optimized SNEDDS. The pitavastatin-loaded SNEDDS generated very little RBC lysis as compared to pure pitavastatin powder and blank SNEDDS formulation as shown in Figure 6B.

\subsection{Effect of the SNEDDS Formulation on Lipid Profile}

Pitavastatin at $4 \mathrm{mg} / \mathrm{kg}$ body weight for five weeks reduced low density lipoproteins (LDL-C). Total cholesterol and triglycerides by $54 \%, 38 \%$, and $28 \%$, respectively, in rats fed a fatty mixed diet. The level of HDL-C did not alter considerably [23]. Cinnamon's significant lipolytic action may play a direct role in lipid metabolism, preventing hypercholesterolemia and hypertriglyceridemia and lowering free fatty acids. Cinnamon oil reduces hepatic cholesterol levels by inhibiting HMG Co-A reductase activity and suppressing lipid peroxidation by increasing hepatic antioxidant enzyme activity [41] as shown in Figure 6C,D.

\subsection{Stability Studies}

There was no change in color was observed but a significant $(p<0.05)$ change in self emulsification time was observed. The article size of SPC3 formulation was $106 \pm 2.45$, $109 \pm 2.21$, and $113 \pm 2.14 \mathrm{~nm}$ at 30, 60 and 90 days, respectively. The value of zeta potential was $-28,-25$, and -21 at 30,60 , and 90 days, respectively. 


\subsection{CytotoxicityS}

We examined the viability of caco-2 cell cultures treated with pitavastatin, cinnamon oil, PEG 400, Tween 80, and SPC3 formulation. The results showed that SPC3 in culture medium did not affect the viability of these cells at the dose used in the study. The cell viability plot showed that more than $86 \%$ cells were viable after $48 \mathrm{~h}$ of incubation with SPC3 formulation as shown in Figure 7A. No alteration of cell morphology of the cell lines was observed under the microscope.

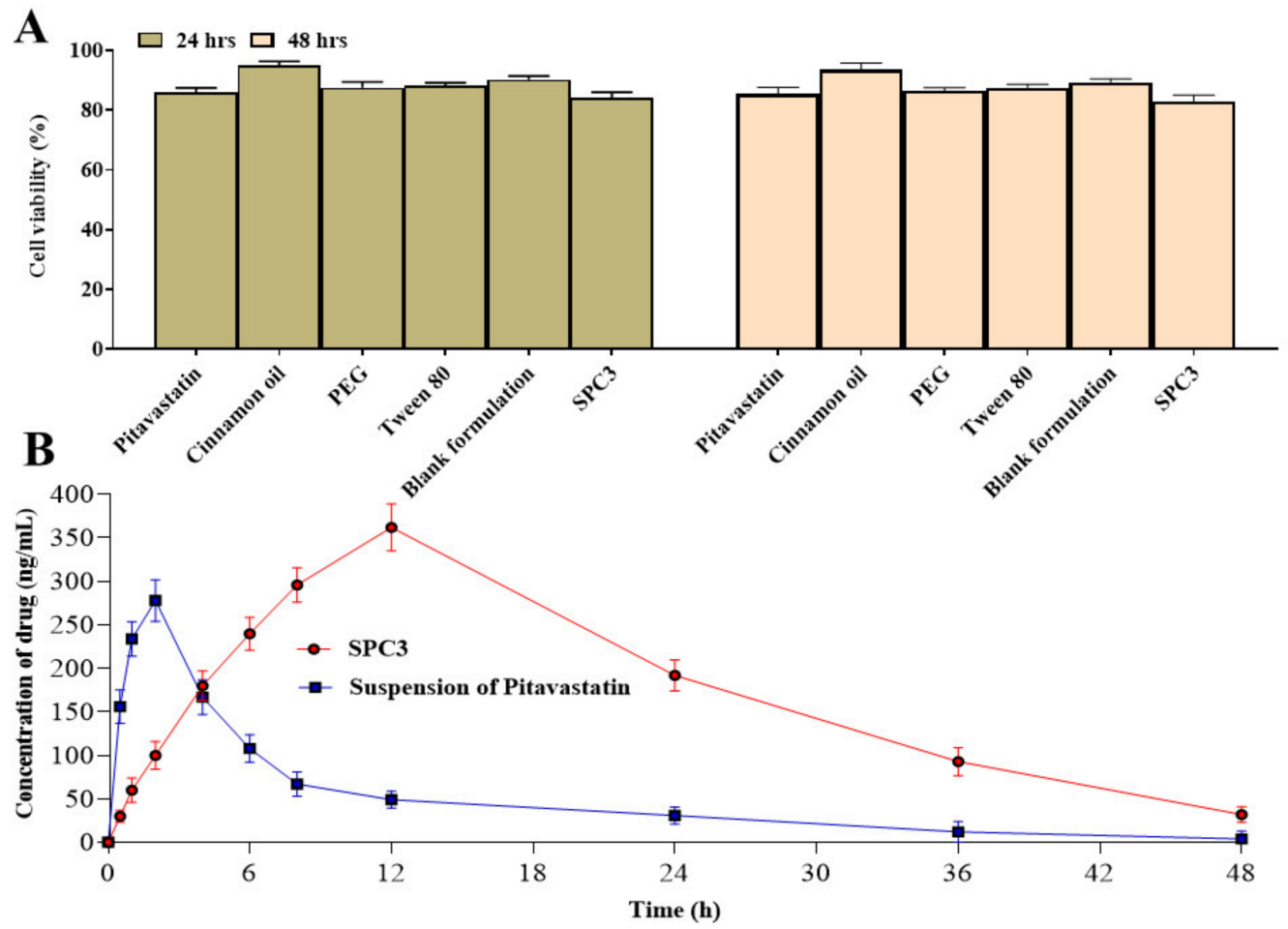

Figure 7. Cytotoxicity study of drug, excipients, blank formulation and SPC3 (A) and pharmacokinetic analysis of pitavastatin from SPC3 (B).

\subsection{Pharmacokinetic Analysis}

Table 4 shows the pharmacokinetic properties of pitavastatin based on the plasma concentration versus time profile. The reference formulation (suspension of pitavastatin) had a $C_{\max }$ of $278 \pm 3.609 \mathrm{ng} / \mathrm{mL}$, while the SPC3 SNEDDS had a $C_{\max }$ of $362 \pm 4.786 \mathrm{ng} / \mathrm{mL}(p<0.05)$. The SPC3 SNEDDS and suspension of pitavastatin had $T_{\max }$ of $12 \pm 1.543 \mathrm{~h}$ and $2 \pm 0.543 \mathrm{~h}$ $(p=0.002)$, respectively as shown in Figure 7B. The SPC3 SNEDDS had a greater AUC0- $\infty$ $9338 \pm 9.876 \mathrm{ng} / \mathrm{mL} . \mathrm{h}(p=0.001)$ than the suspension of pitavastatin $(2478 \pm 6.409 \mathrm{ng} / \mathrm{mL} . \mathrm{h})$. The MRT of SPC3 SNEDDS and suspension of pitavastatin were $22.49 \pm 2.345$ and $13.09 \pm 1.059 \mathrm{~h}$, respectively. The greater MRT value suggested that the drug in the SPC3 SNEDDS formulation was released more slowly than the suspension of pitavastatin. When compared to suspension of pitavastatin, the SPC3 SNEDDS had a greater relative bioavailability. To summarize, when comparing drug retention duration in the blood, $C_{\text {max }}$, and AUC values, SPC3 SNEDDS provides better in vivo behavior than suspension of pitavastatin. 
Table 4. Parameters of pharmacokinetics of SPC3 and suspension of pitavastatin.

\begin{tabular}{ccc}
\hline Parameters & SPC3 (Test Formulation) & $\begin{array}{c}\text { Suspension of Pitavastatin } \\
\text { (Reference Formulation) }\end{array}$ \\
\hline$t_{\max }(\mathrm{h})$ & $12 \pm 1.543$ & $2 \pm 0.543$ \\
\hline$C_{\max }(\mathrm{ng} / \mathrm{mL})$ & $362 \pm 4.786$ & $278 \pm 3.609$ \\
\hline$t_{1 / 2}(\mathrm{~h})$ & $12.24 \pm 2.345$ & $2.12 \pm 0.678$ \\
\hline$A U C_{0-t}(\mathrm{ng} / \mathrm{mL} . \mathrm{h})$ & $7696 \pm 12.789$ & $2257 \pm 5.785$ \\
\hline$A U C_{0-\infty}(\mathrm{ng} / \mathrm{mL} \cdot \mathrm{h})$ & $9338 \pm 9.876$ & $2478 \pm 6.409$ \\
\hline$A U M C_{0-\infty}(\mathrm{ng} / \mathrm{mL} \cdot \mathrm{h})$ & $210,039 \pm 20.897$ & $60,598 \pm 10.762$ \\
\hline$M R T(\mathrm{~h})$ & $22.49 \pm 2.345$ & $13.09 \pm 1.059$ \\
\hline
\end{tabular}

\section{Conclusions}

Finally, based on pitavastatin solubility data, we produced several self-emulsifying formulations. Cinnamon oil (40\%), Tween 80 (40\%), and PEG $400(20 \%)$ were shown to have the optimum self-emulsification properties for pitavastatin. It was observed that the particle size and droplets size of the optimized SPC3 SNEDDS were $104 \pm 1.50 \mathrm{~nm}$ and $109 \pm 0.51$, respectively, which improved the compound's solubility. The zeta potential criterion for stability was met by the improved formulation. In-house repeatable and reliable HPLC method was developed for the measurement of Pitavastatin in rat plasma. In vivo investigation showed that the optimized pitavastatin SNEDDS had a greater $C_{\max }$ $(p=0.003)$ and AUC $(p=0.001)$ than the reference formulation (pitavastatin suspension), indicating a significant improvement in bioavailability. Efficient digestion of SNEDDS in the presence of bile salts enhances drug release, which could improve drug penetration through the intestinal mucosa, thereby improving drug bioavailability. Moreover, the observed plasma time concentration in rat plasma analyzed with Kinetica provides a comprehensive pharmacokinetic investigation of pitavastatin SNEDDS and is the best fit for the one compartment model. Lastly, when the pitavastatin SNEDDS were compared to the marketed formulation (pitavastatin suspension), the prepared SNEDDS had greater bioavailability. This could be due to the fact of a collective mechanism including nano-sized dispersion with a larger surface area, which results in improved drug diffusion, enhanced drug solubility, lymphatic bypass share and mucosal permeability.

Author Contributions: Conceptualization, G.A., S.S., A.R. and M.H.; methodology, M.A., H.U.K., S.M., M.H. and O.I.; software, A.M.E.S., M.Y.A.; validation, H.U.K., S.M. and A.R.; formal analysis, A.K.; investigation, A.M.E.S., M.A.S.A.; resources, M.M.G.; data curation, M.H. and O.I.; writingoriginal draft preparation, M.A., M.A.A., M.Y.A. and G.A.; writing-review and editing, M.M.G., H.U.K., S.M. and S.S.; visualization, M.A.A.; supervision, G.A.; project administration, G.A. and A.K.; funding acquisition, A.K., M.A.A., M.M.G. and M.A.S.A. All authors have read and agreed to the published version of the manuscript.

Funding: This research received no external funding.

Institutional Review Board Statement: The animal study protocol was approved by the Institutional Review Board of Government College University Faisalabad (GCUF/2021/016 and 20 June 2021).

Data Availability Statement: Not applicable.

Acknowledgments: The authors would like to acknowledge the Taif University Researchers Supporting Project number (TURSP-2020/68), Taif University, Taif, Saudi Arabia. The authors deeply acknowledge the Researchers Supporting Program (TUMA-Project-2021-6), Al Maarefa University, Riyadh, Saudi Arabia for supporting steps of this work. The authors would like to thank the Deanship of scientific research at Umm Al-Qua University for supporting this work by grant code (22UQU4290565DSR04).

Conflicts of Interest: The authors declare no conflict of interest. 


\section{References}

1. Sudhakaran, S.; Bottiglieri, T.; Tecson, K.M.; Kluger, A.Y.; McCullough, P.A.; Bottlieri, T. Alteration of lipid metabolism in chronic kidney disease, the role of novel antihyperlipidemic agents, and future directions. Rev. Cardiovasc. Med. 2019, 19, 77-88.

2. Ashman, J.J.; Beresovsky, V. Multiple Chronic Conditions among US Adults Who Visited Physician Offices: Data from the National Ambulatory Medical Care Survey; National Center for Chronic Disease Prevention and Health Promotion: New York, NY, USA, 2009.

3. Li, M.; Wang, X.; Li, X.; Chen, H.; Hu, Y.; Zhang, X.; Tang, X.; Miao, Y.; Tian, G.; Shang, H. Statins for the primary prevention of coronary heart disease. BioMed Res. Int. 2019, 2019, 4870350. [CrossRef] [PubMed]

4. Homayun, B.; Lin, X.; Choi, H.-J. Challenges and recent progress in oral drug delivery systems for biopharmaceuticals. Pharmaceutics 2019, 11, 129. [CrossRef] [PubMed]

5. Nomura, S. Pitavastatin in the management of hypercholesterolemia. Clin. Med. Ther. 2009, 1, 1477-1488. [CrossRef]

6. Saito, Y.; Yamada, N.; Teramoto, T.; Itakura, H.; Hata, Y.; Nakaya, N.; Mabuchi, H.; Tushima, M.; Sasaki, J.; Ogawa, N. A randomized, double-blind trial comparing the efficacy and safety of pitavastatin versus pravastatin in patients with primary hypercholesterolemia. Atherosclerosis 2002, 162, 373-379. [CrossRef]

7. Caparica, R.; Júlio, A.; Baby, A.R.; Araújo, M.E.M.; Fernandes, A.S.; Costa, J.G.; Santos de Almeida, T. Choline-amino acid ionic liquids as green functional excipients to enhance drug solubility. Pharmaceutics 2018, 10, 288. [CrossRef]

8. Nandi, U.; Ajiboye, A.L.; Patel, P.; Douroumis, D.; Trivedi, V. Preparation of Solid Dispersions of Simvastatin and Soluplus Using a Single-Step Organic Solvent-Free Supercritical Fluid Process for the Drug Solubility and Dissolution Rate Enhancement. Pharmaceuticals 2021, 14, 846. [CrossRef]

9. Shrestha, H.; Bala, R.; Arora, S. Lipid-based drug delivery systems. J. Pharm. 2014, 2014, 801820. [CrossRef]

10. Gao, P.; Rush, B.D.; Pfund, W.P.; Huang, T.; Bauer, J.M.; Morozowich, W.; Kuo, M.S.; Hageman, M.J. Development of a supersaturable SEDDS (S-SEDDS) formulation of paclitaxel with improved oral bioavailability. J. Pharm. Sci. 2003, 92, 2386-2398. [CrossRef]

11. Jyothi, B.J.; Sreelakshmi, K. Design and evaluation of self-nanoemulsifying drug delivery system of flutamide. J. Young Pharm. 2011, 3, 4-8. [CrossRef]

12. Fatouros, D.G.; Bergenstahl, B.; Mullertz, A. Morphological observations on a lipid-based drug delivery system during in vitro digestion. Eur. J. Pharm. Sci. 2007, 31, 85-94. [CrossRef]

13. Ramani, V.; Chauhan, S.; Joshi, J.; Ghelani, T.; Deshmukh, G.; AK, S.; Patel, J.; Philips, M.; Gupta, R. Formulation and evaluation of nanoparticles of HMG-CoA reductase inhibitor. Pharma Sci. Monit. 2011, 2, 4258.

14. Tiwari, N.; Sivakumar, A.; Mukherjee, A.; Chandrasekaran, N. Enhanced antifungal activity of Ketoconazole using rose oil based novel microemulsion formulation. J. Drug Deliv. Sci. Technol. 2018, 47, 434-444. [CrossRef]

15. Tripathi, S.; Kushwah, V.; Thanki, K.; Jain, S. Triple antioxidant SNEDDS formulation with enhanced oral bioavailability: Implication of chemoprevention of breast cancer. Nanomedicine 2016, 12, 1431-1443. [CrossRef]

16. Parashar, P.; Mangla, B.; Joshi, S.K. Design \& development of novel lipid based carrier system for delivery of pitavastatin calcium Int. J. Pharm. Sci. Res. 2016, 7, 5030.

17. Atef, E.; Belmonte, A.A. Formulation and in vitro and in vivo characterization of a phenytoin self-emulsifying drug delivery system (SEDDS). Eur. J. Pharm. Sci. 2008, 35, 257-263. [CrossRef]

18. Kazi, M.; Alhajri, A.; Alshehri, S.M.; Elzayat, E.M.; Al Meanazel, O.T.; Shakeel, F.; Noman, O.; Altamimi, M.A.; Alanazi, F.K. Enhancing oral bioavailability of apigenin using a bioactive self-nanoemulsifying drug delivery system (Bio-SNEDDS): In vitro, in vivo and stability evaluations. Pharmaceutics 2020, 12, 749. [CrossRef]

19. Inugala, S.; Eedara, B.B.; Sunkavalli, S.; Dhurke, R.; Kandadi, P.; Jukanti, R.; Bandari, S. Solid self-nanoemulsifying drug delivery system (S-SNEDDS) of darunavir for improved dissolution and oral bioavailability: In vitro and in vivo evaluation. Eur. J. Pharm. Sci. 2015, 74, 1-10. [CrossRef]

20. Balakumar, K.; Raghavan, C.V.; Abdu, S. Self nanoemulsifying drug delivery system (SNEDDS) of rosuvastatin calcium: Design, formulation, bioavailability and pharmacokinetic evaluation. Colloids Surf. B 2013, 112, 337-343. [CrossRef]

21. Balakrishnan, P.; Lee, B.-J.; Oh, D.H.; Kim, J.O.; Hong, M.J.; Jee, J.-P.; Kim, J.A.; Yoo, B.K.; Woo, J.S.; Yong, C.S. Enhanced oral bioavailability of dexibuprofen by a novel solid self-emulsifying drug delivery system (SEDDS). Eur. J. Pharm. Biopharm. 2009, 72, 539-545. [CrossRef]

22. Başpınar, Y.; Gündoğdu, E.; Köksal, Ç.; Karasulu, E. Pitavastatin-containing nanoemulsions: Preparation, characterization and in vitro cytotoxicity. J. Drug Deliv. Sci. Technol. 2015, 29, 117-124. [CrossRef]

23. Kazi, M.; Al-Swairi, M.; Ahmad, A.; Raish, M.; Alanazi, F.K.; Badran, M.M.; Khan, A.A.; Alanazi, A.M.; Hussain, M.D. Evaluation of self-nanoemulsifying drug delivery systems (SNEDDS) for poorly water-soluble talinolol: Preparation, in vitro and in vivo assessment. Front. Pharmacol. 2019, 10, 459. [CrossRef]

24. Beg, S.; Sandhu, P.S.; Batra, R.S.; Khurana, R.K.; Singh, B. QbD-based systematic development of novel optimized solid selfnanoemulsifying drug delivery systems (SNEDDS) of lovastatin with enhanced biopharmaceutical performance. Drug Deliv. 2015, 22, 765-784. [CrossRef]

25. Fischer, D.; Li, Y.; Ahlemeyer, B.; Krieglstein, J.; Kissel, T. In vitro cytotoxicity testing of polycations: Influence of polymer structure on cell viability and hemolysis. Biomaterials 2003, 24, 1121-1131. [CrossRef]

26. Hui, C.; Cheung, B.; Lau, G. Pharmacokinetics of pitavastatin in subjects with Child-Pugh A and B cirrhosis. Br. J. Clin. Pharmacol. 2005, 59, 291-297. [CrossRef] 
27. Eid, A.M.; El-Enshasy, H.A.; Aziz, R.; Elmarzugi, N.A. The preparation and evaluation of self-nanoemulsifying systems containing Swietenia oil and an examination of its anti-inflammatory effects. Int. J. Nanomed. 2014, 9, 4685.

28. Kang, J.H.; Oh, D.H.; Oh, Y.-K.; Yong, C.S.; Choi, H.-G. Effects of solid carriers on the crystalline properties, dissolution and bioavailability of flurbiprofen in solid self-nanoemulsifying drug delivery system (solid SNEDDS). Eur. J. Pharm. Biopharm. 2012, 80, 289-297. [CrossRef]

29. Kassem, A.A.; Mohsen, A.M.; Ahmed, R.S.; Essam, T.M. Self-nanoemulsifying drug delivery system (SNEDDS) with enhanced solubilization of nystatin for treatment of oral candidiasis: Design, optimization, in vitro and in vivo evaluation. J. Mol. Liq. 2016, 218, 219-232. [CrossRef]

30. Syukri, Y.; Fitriani, H.; Pandapotan, H.; Nugroho, B.H. Formulation, characterization and stability of ibuprofen-loaded self-nano emulsifying drug delivery system (SNEDDS). Indones. J. Pharm. 2019, 30, 105-113. [CrossRef]

31. Tayel, S.A.; El-Nabarawi, M.A.; Tadros, M.I.; Abd-Elsalam, W.H. Duodenum-triggered delivery of pravastatin sodium via enteric surface-coated nanovesicular spanlastic dispersions: Development, characterization and pharmacokinetic assessments. Int. J. Pharm. 2015, 483, 77-88. [CrossRef]

32. Li, Y.-q.; Kong, D.-x.; Wu, H. Analysis and evaluation of essential oil components of cinnamon barks using GC-MS and FTIR spectroscopy. Ind. Crops Prod. 2013, 41, 269-278. [CrossRef]

33. Philip, D. Honey mediated green synthesis of silver nanoparticles. Spectrochim. Acta Part A 2010, 75, 1078-1081. [CrossRef] [PubMed]

34. Ren, W.; Tian, G.; Jian, S.; Gu, Z.; Zhou, L.; Yan, L.; Jin, S.; Yin, W.; Zhao, Y. TWEEN coated NaYF 4: Yb, Er/NaYF4 core/shell upconversion nanoparticles for bioimaging and drug delivery. RSC Adv. 2012, 2, 7037-7041. [CrossRef]

35. Kuncahyo, I.; Choiri, S.; Fudholi, A.; Rohman, A.; Martien, R. Understanding the effect of lipid formulation loading and ethanol as a diluent on solidification of pitavastatin super-saturable SNEDDS using factorial design approach. Res. Pharm. Sci. 2019, 14, 378.

36. Terata, Y.; Saito, T.; Fujiwara, Y.; Hasegawa, H.; Miura, H.; Watanabe, H.; Chiba, Y.; Kibira, S.; Miura, M. Pitavastatin inhibits upregulation of intermediate conductance calcium-activated potassium channels and coronary arteriolar remodeling induced by long-term blockade of nitric oxide synthesis. Pharmacology 2003, 68, 169-176. [CrossRef]

37. Alam, M.A.; Al-Jenoobi, F.I.; Al-Mohizea, A.M. Everted gut sac model as a tool in pharmaceutical research: Limitations and applications. J. Pharm. Pharmacol. 2012, 64, 326-336. [CrossRef]

38. Naz, Z.; Ahmad, F.J. Curcumin-loaded colloidal carrier system: Formulation optimization, mechanistic insight, ex vivo and in vivo evaluation. Int. J. Nanomed. 2015, 10, 4293. [CrossRef]

39. Kojima, Y.; Ishida, T.; Sun, L.; Yasuda, T.; Toh, R.; Rikitake, Y.; Fukuda, A.; Kume, N.; Koshiyama, H.; Taniguchi, A. Pitavastatin decreases the expression of endothelial lipase both in vitro and in vivo. Cardiovasc. Res. 2010, 87, 385-393. [CrossRef]

40. Wang, L.; Wang, Y.; Chen, A.; Teli, M.; Kondo, R.; Jalali, A.; Fan, Y.; Liu, S.; Zhao, X.; Siegel, A. Pitavastatin slows tumor progression and alters urine-derived volatile organic compounds through the mevalonate pathway. FASEB J. 2019, 33, 13710-13721. [CrossRef]

41. Mahmood, S.; Talat, A.; Karim, S.; Khurshid, R.; Zia, A. Effect of cinnamon extract on blood glucose level and lipid profile in alloxan induced diabetic rats. Pak. J. Physiol. 2011, 7, 13-16. 